\title{
Pure $\mathrm{Cs}_{4} \mathrm{PbBr}_{6}$ : Highly Luminescent Zero- Dimensional Perovskite Solids
}

\author{
Makhsud I. Saidaminov, ${ }^{\dagger}$ Jawaher Almutlaq, ${ }^{\dagger}$ Smritakshi Sarmah, Ibrahim Dursun, Ayan A. Zhumekenov, \\ Raihana Begum, Jun Pan, Namchul Cho, Omar F. Mohammed,* and Osman M. Bakr* \\ Division of Physical Sciences and Engineering, KAUST Solar Center, King Abdullah University of Science and Technology (KAUST), \\ Thuwal 23955-6900, Kingdom of Saudi Arabia
}

\section{Supporting Information}

ABSTRACT: So-called zero-dimensional perovskites, such as $\mathrm{Cs}_{4} \mathrm{PbBr}_{6}$, promise outstanding emissive properties. However, $\mathrm{Cs}_{4} \mathrm{PbBr}_{6}$ is mostly prepared by melting of precursors that usually leads to a coformation of undesired phases. Here, we report a simple low-temperature solution-processed synthesis of pure $\mathrm{Cs}_{4} \mathrm{PbBr}_{6}$ with remarkable emission properties. We found that pure $\mathrm{Cs}_{4} \mathrm{PbBr}_{6}$ in solid form exhibits a $45 \%$ photoluminescence quantum yield (PLQY), in contrast to its three-dimensional counterpart, $\mathrm{CsPbBr}$, which exhibits more than 2 orders of magnitude lower PLQY. Such a PLQY of $\mathrm{Cs}_{4} \mathrm{PbBr}_{6}$ is significantly higher than that of other solid forms of lower-dimensional metal halide perovskite derivatives and perovskite nanocrystals. We attribute this dramatic increase in PL to the high exciton binding energy, which we estimate to be $\sim 353 \mathrm{meV}$, likely
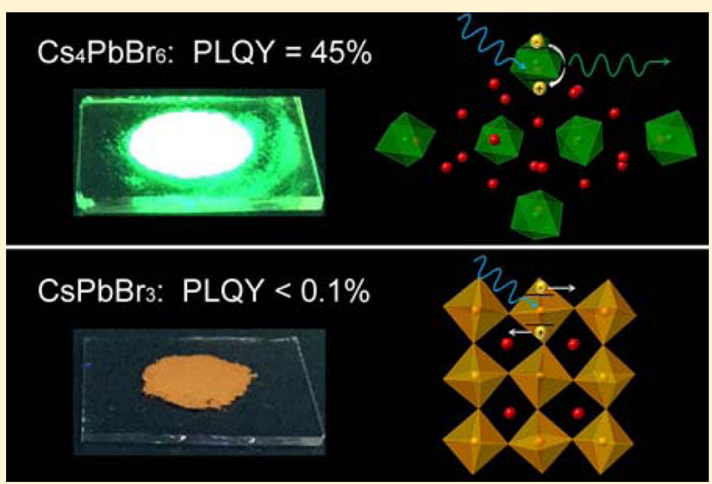
induced by the unique Bergerhoff-Schmitz-Dumont-type crystal structure of $\mathrm{Cs}_{4} \mathrm{PbBr}_{6}$, in which metal-halide-comprised octahedra are spatially confined. Our findings bring this class of perovskite derivatives to the forefront of color-converting and light-emitting applications.

$\mathrm{T}$ he photoluminescence quantum yield (PLQY) of semiconductor materials correlates with their trap state densities and applicability for optoelectronic applications like solar cells, color converters, lasers, lightemitting diodes, and others. ${ }^{1-3}$ An ideal emitter exhibits nearunity PLQY due to absence of trap states within its band gap. ${ }^{4}$ Recent reports on perovskite single crystals have estimated ultralow trap state densities, on the order of $\sim 10^{10} \mathrm{~cm}^{-3}$., ${ }^{5,6}$ Yet those bulk perovskites are not optically emissive, most likely due to the shared octahedra of the crystal structure that prevent quantum confinement of the charge carriers. As a result, their excitons have extremely low binding energies $(\sim 15-50 \mathrm{meV}$, which is on the order of thermal energy at room temperature) and thus readily dissociate to free carriers. ${ }^{7-9}$ Quantum confinement and the ensuing high PLQY are realized physically in perovskite quantum dots due to their nanoscale physical sizes (stabilized by ligands) $)^{10,11}$ and in perovskite thin films due to the microscale grain sizes. ${ }^{12,13}$ Unfortunately, the PLQY of quantum dots markedly decreases when they are made into solid form ${ }^{14}$ because of the loss of capping ligands causing further aggregation. On the other hand, in thin films perovskites, the abundance of grain boundaries is detrimental to the material's stability. ${ }^{15}$

An alternative attractive approach to achieve quantum confinement is by reducing the structural dimensionality of perovskites. $^{16-18}$ The general formula of perovskites can be written as $\mathrm{A}_{n} \mathrm{BX}_{2+n}$, where $\mathrm{A}$ is a monovalent cation like $\mathrm{CH}_{3} \mathrm{NH}_{3}{ }^{+}, \mathrm{Cs}^{+}$, and so forth, $\mathrm{B}$ is a divalent metal, usually $\mathrm{Pb}^{2+}$ or $\mathrm{Sn}^{2+}$, and $\mathrm{X}$ is a halogen anion. When $n=1$, the perovskite is referred to as a three-dimensional (3D) perovskite. For instance, $\mathrm{CsPbBr}_{3}$ is a $3 \mathrm{D}$ perovskite, where the crystal structure is based on the corner-shared $\mathrm{PbBr}_{6}{ }^{4-}$ octahedra (Figure 1a). For $n=2-4$, the structure is often referred to as low-dimensional perovskites in which the octahedra form planes (if $n=2$, they are called 2D), chains (if $n=3,1 \mathrm{D}$ ), and isolated dots (if $n=4,0 \mathrm{D}) .{ }^{19,20}$ Recent reports have

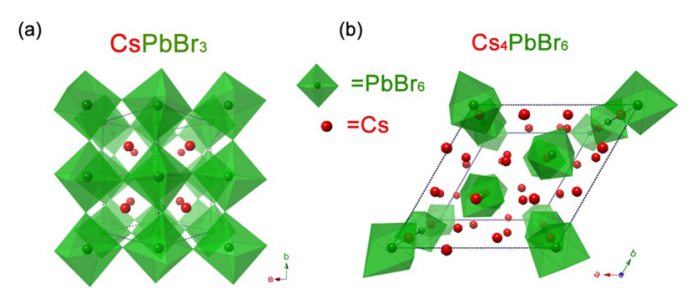

Figure 1. Crystal structure of (a) $\mathrm{CsPbBr}_{3}$ and (b) $\mathrm{Cs}_{4} \mathrm{PbBr}_{6}$ featuring corner-shared and isolated $\mathrm{PbBr}_{6}{ }^{4-}$ octahedra, respectively.

Received: August 30, 2016

Accepted: September 25, 2016

Published: September 26, 2016 


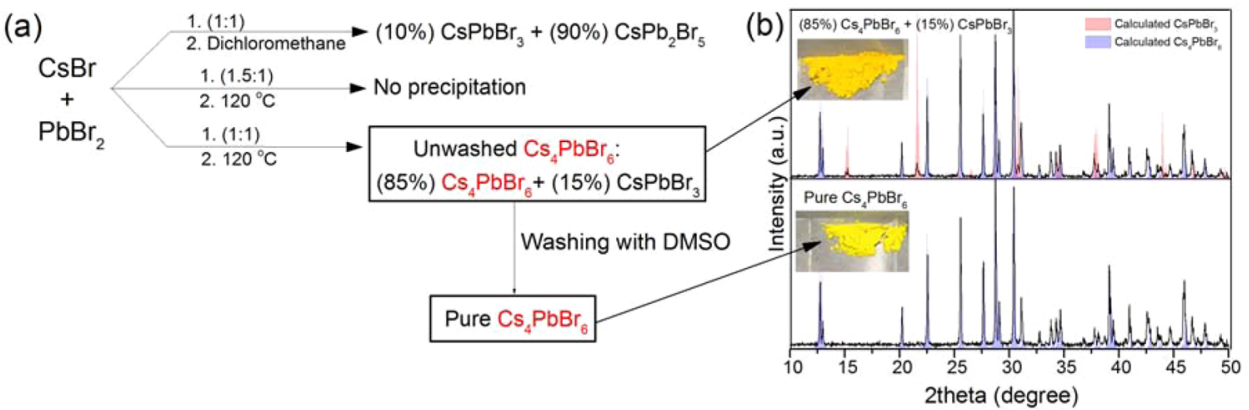

Figure 2. (a) Schematic representation of the optimization method for the synthesis and purification of $\mathrm{Cs}_{4} \mathrm{PbBr}_{6}$ (percentages represent the ratios of XRD peak intensities); (b) PXRD patterns of as-synthesized unwashed $\mathrm{Cs}_{4} \mathrm{PbBr}_{6}$ and pure $\mathrm{Cs}_{4} \mathrm{PbBr}_{6}$ along with the calculated spectra of the same. (Insets) Picture of the corresponding solids.

(a)

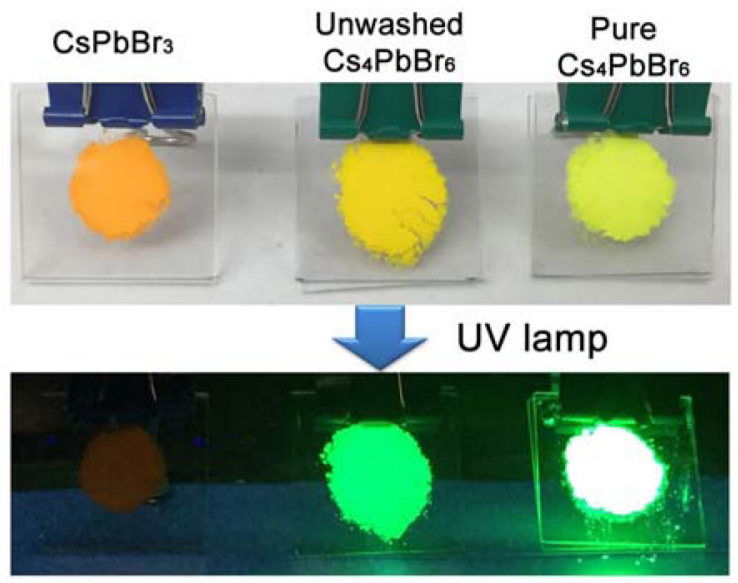

(b)

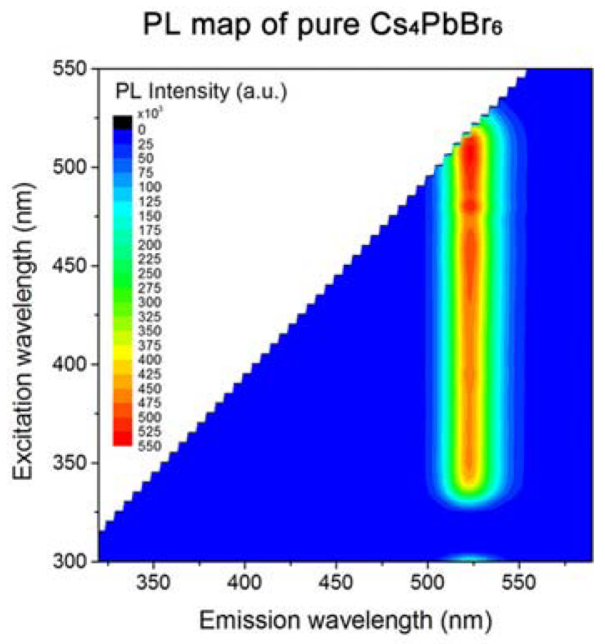

(c)

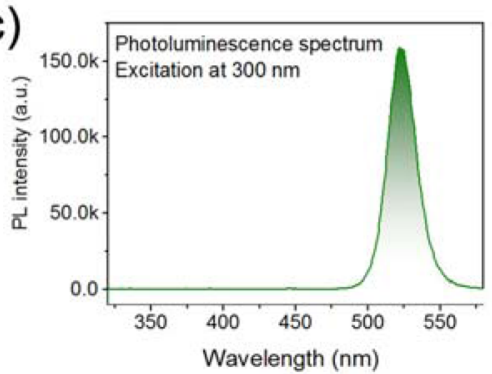

(d)

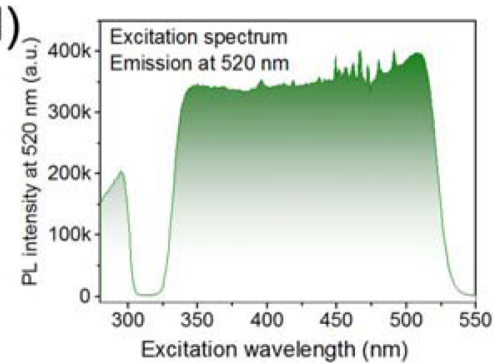

(e)

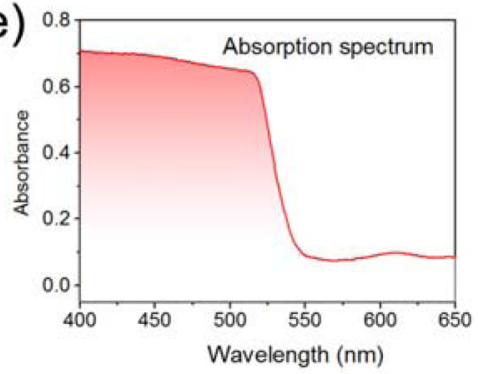

Figure 3. (a) Ground $\mathrm{Cs} \mathrm{PbBr}_{3}$, unwashed $\mathrm{Cs}_{4} \mathrm{PbBr}_{6}$, and pure $\mathrm{Cs}_{4} \mathrm{PbBr}_{6}$ powders on the glass slides under ambient and UV light (365 nm); (b) PL intensity as a function of excitation wavelengths for the pure $\mathrm{Cs}_{4} \mathrm{PbBr}_{6}$; (c) steady-state PL; (d) excitation spectrum at a PL wavelength of $520 \mathrm{~nm}$; and (e) absorption spectrum of pure $\mathrm{Cs}_{4} \mathrm{PbBr}_{6}$.

demonstrated a remarkable increase in PLQY upon reducing the dimensionality of perovskites due to the increase in the exciton binding energy. ${ }^{17,21,22}$ For example, the PLQY of 2D lead bromide based perovskite solids was reported to be $\sim 9 \%^{22}$ (compared to $\sim 0.1 \%$ for $3 \mathrm{D}$, vide infra). Also, $\mathrm{CsPb}_{2} \mathrm{Br}_{5}$ with 2D-like structure showed significantly strong emission. Its PLQY was reported to be $\sim 87 \%$ in solution and expected to be also high in solid form compared to the $3 \mathrm{D} \mathrm{CsPbBr} 3$ (the actual PLQY for the $\mathrm{CsPb}_{2} \mathrm{Br}_{5}$ solid was not reported). ${ }^{23}$ These intriguing findings drew our attention and motivated us to explore the extreme case when those octahedra are isolated by Cs bridges to form OD perovskites, ${ }^{24,25}$ for which we hypothesized that exceptionally high PLQY could be achieved. The Bergerhoff-Schmitz-Dumont-type crystal structure (the proper name for the crystal phase) ${ }^{26}$ in $\mathrm{Cs}_{4} \mathrm{PbBr}_{6}$ (Figure $1 \mathrm{~b}$ ) adopts a configuration in which the $\mathrm{Cs}^{+}$ions minimize the electronic overlap between adjacent octahedra, resulting in localized states that are confined to the individual octahedra. ${ }^{27}$ The optical properties of $\mathrm{Cs}_{4} \mathrm{PbBr}_{6}$ have been partially investigated in the literature, but issues like synthesis and coexistence of $\mathrm{CsPBr}_{3}$ have hindered its proper characterization. In particular, the origin of luminescence in these mixtures has been a point of controversy in the literature. Some studies attributed its PL to the presence of $\mathrm{CsPbBr}_{3},{ }^{27-29}$ while others attributed it to the intrinsic property of $\mathrm{Cs}_{4} \mathrm{PbBr}_{6} \cdot{ }^{30,31} \mathrm{In}$ this study, we present a simple solution-processed chemical method to synthesize pure $\mathrm{Cs}_{4} \mathrm{PbBr}_{6}$ solids, which enabled us to study and reveal the material's true remarkable optical properties. 

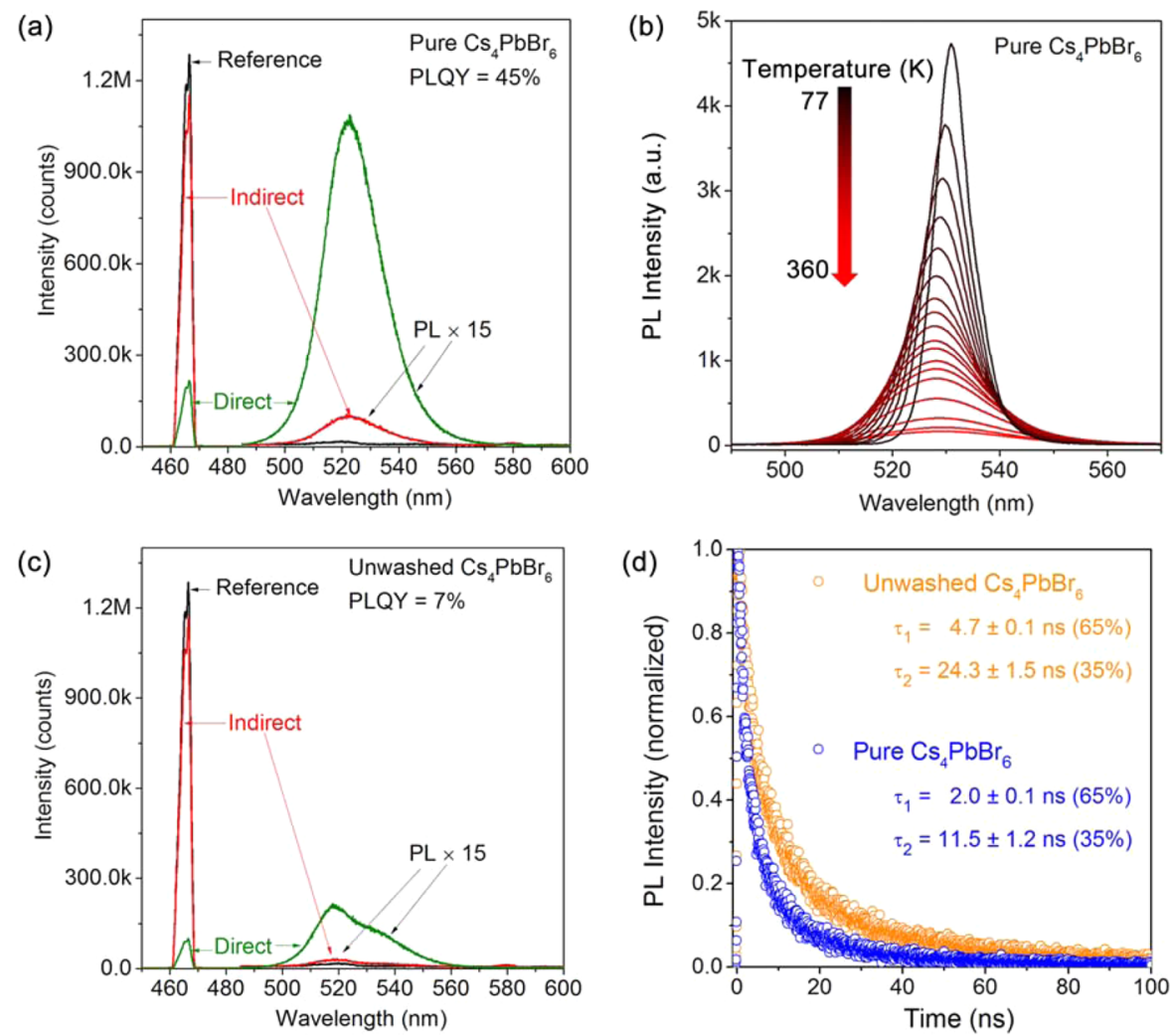

Figure 4. (a) The PL spectra of pure $\mathrm{Cs}_{4} \mathrm{PbBr}_{6}$ for PLQY measurement using an integrating sphere. The PL spectra were enlarged by a factor of 15 for clarity. (b) Temperature-dependent PL spectra of pure $\mathrm{Cs}_{4} \mathrm{PbBr}_{6}$ from 77 to $360 \mathrm{~K}$. (c) The $\mathrm{PL}$ spectra of unwashed $\mathrm{Cs}_{4} \mathrm{PbBr}_{6}$ for PLQY measurement using an integrating sphere. (d) PL lifetime decay of pure and unwashed $\mathrm{Cs}_{4} \mathrm{PbBr}_{6} \mathrm{under}_{50} \mu \mathrm{J} / \mathrm{cm}^{2} \mathrm{pump}$ fluence.

As aforementioned, one of the fundamental problems that needs to be addressed is the separation of $\mathrm{Cs}_{4} \mathrm{PbBr}_{6}$ from any other additional phases. Figure $2 \mathrm{a}$ summarizes some of the explored parameters to arrive at pure $\mathrm{Cs}_{4} \mathrm{PbBr}_{6}$. We started with rapid precipitation from $\mathrm{CsBr} / \mathrm{PbBr}_{2}$ (1:1 molar ratio) in dimethyl sulfoxide (DMSO) solution by adding antisolvent (dichloromethane). However, it resulted in a mixture of undesired phases- $\mathrm{Cs} \mathrm{PbBr}_{3}$ and $\mathrm{CsPb}_{2} \mathrm{Br}_{5}$ (Figure S1). Then, we turned to inverse solubility, in which precipitation occurs when the solution is heated; this phenomenon was recently utilized to synthesize a number of hybrid perovskite bulk crystals and crystalline films of high quality. ${ }^{32-37}$ We observed that $\mathrm{CsBr} / \mathrm{PbBr}_{2}\left(1: 1\right.$ molar ratio) in $\mathrm{DMSO}$ at $120{ }^{\circ} \mathrm{C}$ produces predominantly $\mathrm{Cs}_{4} \mathrm{PbBr}_{6}$ solid with some traces of $\mathrm{CsPbr}_{3}$ (Figure $2 \mathrm{~b}$, top). Because $\mathrm{Cs}_{4} \mathrm{PbBr}_{6}$ is richer in cesium compared to $\mathrm{CsPbBr}_{3}$, we speculated that the increase of $\mathrm{CsBr}$ precursor concentration in solution would induce precipitation of only the $\mathrm{Cs}_{4} \mathrm{PbBr}_{6}$ phase, but further increase in $\mathrm{CsBr}$ concentration to the molar ratio of $1.5: 1$ did not show any precipitation (Figure S2), which could be due to the limited solubility of $\mathrm{CsBr}$ in $\mathrm{DMSO}$. Undissolved $\mathrm{CsBr}$ partially reacts with $\mathrm{PbBr}_{2}$, thus decreasing the final concentration of $\mathrm{PbBr}_{2}$ in solution (Figure S3). We further investigated the solubility of these perovskites and found that DMSO dissolves $\mathrm{CsPbBr}_{3}$ but not $\mathrm{Cs}_{4} \mathrm{PbBr}_{6}$ (Figure S4). Thus, we turned back to the initial $\mathrm{CsBr} / \mathrm{PbBr}_{2}$ (1:1) solution in DMSO. We collected the precipitate that was formed at $120{ }^{\circ} \mathrm{C}$ and washed it with DMSO. This step selectively removes $\mathrm{Cs} \mathrm{PbBr}_{3}$, leaving behind a pure $\mathrm{Cs}_{4} \mathrm{PbBr}_{6}$ phase. Powder X-ray diffraction (PXRD) of the purified sample confirmed the presence of monophasic $\mathrm{Cs}_{4} \mathrm{PbBr}_{6}$, which is consistent with the calculated PXRD
(Figure $2 \mathrm{~b}$, bottom). A high-resolution $\mathrm{XRD}$ scan at $2 \theta=$ 13.5-18 ${ }^{\circ} \mathrm{C}$ confirmed the absence of $\mathrm{CsPBr}_{3}$ in our purified samples (Figure S5). The details of the optimized recipe can be found in the Supporting Information. During the preparation of this Letter, Y. Rakita et al. reported a highly luminescent side product formed during the synthesis of $\mathrm{CsPbB}_{3}$, which, according to $\mathrm{XRD}$, consists of both $\mathrm{Cs}_{4} \mathrm{PbBr}_{6}$ and $\mathrm{CsPbBr}_{3}{ }^{31}$ However, the problem of $\mathrm{OD}$ purification from the coexisting $3 \mathrm{D}$ perovskite was not addressed, which, as we will show later, obscures the optical properties of the $0 \mathrm{D} \mathrm{Cs}_{4} \mathrm{PbBr}_{6}$ and has a severe detrimental effect on the PLQY.

Next, we studied the materials' optical properties. The ground $3 \mathrm{D} \mathrm{CsPBr}_{3}$ is not luminescent under UV light, whereas the unwashed $\mathrm{Cs}_{4} \mathrm{PbBr}_{6}$ solid is green and the purified one is bright green under the same conditions (Figure 3a). Figure $3 b$ shows the dependence of pure $\mathrm{Cs}_{4} \mathrm{PbBr}_{6}$ 's $\mathrm{PL}$ intensity on the excitation wavelength. $\mathrm{Cs}_{4} \mathrm{PbBr}_{6}$ exhibits a single PL peak, centered at $520 \mathrm{~nm}$ (Figure 3c), in good agreement with a recent report. ${ }^{31} \mathrm{Cs}_{4} \mathrm{PbBr}_{6}$ has also a strong and stable emission at excitation wavelengths of $\lambda>340 \mathrm{~nm}$ (Figure 3d). The absorption edge of pure $\mathrm{Cs}_{4} \mathrm{PbBr}_{6}$ at $540 \mathrm{~nm}$ (Figure $3 \mathrm{e}$ ) is consistent with the literature values. ${ }^{30}$

To quantify the PL, we measured the PLQY of $0 \mathrm{D} \mathrm{Cs} \mathrm{CbBr}_{6}$ and $3 \mathrm{D} \mathrm{CsPbBr}$ following the method reported by de Mello et al. ${ }^{38}$ While we were not able to accurately measure the PLQY of $3 \mathrm{D}$ perovskite because of low luminescence (PLQY $<0.1 \%$ ), that of the OD perovskite was found to be $\sim 45 \%$ (Figure $4 \mathrm{a}$ ). Alternatively, the PLQY may also be estimated from temperature-dependent PL measurements (Figure 4b). From such a measurement, we deduce $\sim 40 \% \mathrm{PLQY}^{39}$ at room temperature (Figure S6), which is in good agreement with the previous 
Table 1. PLQY and Exciton Binding Energy of Perovskite Solids of Various Dimensionalities

\begin{tabular}{ll} 
dimensionality & \multicolumn{1}{c}{ composition } \\
$3 \mathrm{D}$ & $\mathrm{MAPbX}_{3}$ \\
$2 \mathrm{D}$ & $\left(\mathrm{NH}_{3} \mathrm{C}_{2} \mathrm{H}_{4} \mathrm{OC}_{2} \mathrm{H}_{4} \mathrm{OC}_{2} \mathrm{H}_{4} \mathrm{NH}_{3}\right) \mathrm{PbBr}_{4}$ \\
& $\left(\mathrm{C}_{10} \mathrm{H}_{21} \mathrm{NH}_{3}\right)_{2} \mathrm{PbI}_{4}$ \\
nanocrystals & $\mathrm{CsPBr}_{3}$ \\
0D & $\mathrm{Cs}_{4} \mathrm{PbBr}_{6}$
\end{tabular}

PLQY (\%)
$<0.1^{46}$
$9^{22}$
-
$18^{14}$
$45^{a}$

binding energy $(\mathrm{meV})$ $15-50^{7-9}$

$-$

$370^{47}$

$19-62^{48,49}$

$353^{a}$

${ }^{a}$ Current work.

direct measurement. We speculate that the difference in PLQY between $\mathrm{OD}$ and $3 \mathrm{D}$ perovskites originates from their unique structures. In $3 \mathrm{D}$ perovskite, due to low binding energies of excitons, they dissociate into free carriers and travel across the corner-shared octahedra. ${ }^{7,8}$ In contrast, the generated excitons in the $0 \mathrm{D}$ perovskite are confined within the isolated octahedra. As a result, the exciton binding energy in $\mathrm{Cs}_{4} \mathrm{PbBr}_{6}$ is estimated to be much higher, $353 \pm 40 \mathrm{meV}$ (estimated from temperature-dependent PL measurements, ${ }^{40}$ Figure S6), an order of magnitude higher than that in $3 \mathrm{D}$ perovskites (Table $1) .^{40-44}$ Thus, this dramatic increase in the exciton binding energy is likely responsible for the high PLQY in OD perovskites. Noteworthy, unwashed material $\left(85 \% \mathrm{Cs}_{4} \mathrm{PbBr}_{6}\right.$ and $15 \% \mathrm{CsPbBr}_{3}$ ) showed only $\sim 7 \%$ PLQY (Figure $4 \mathrm{c}$ ), despite the relatively small amount of the $3 \mathrm{D}$ phase present. In addition, its PL spectrum consists of two peaks that originate from both $\mathrm{OD}$ and $3 \mathrm{D}$ perovskites (Figure $4 \mathrm{c}$ ). These findings again demonstrate the importance of purification to achieve a homogeneous PL and high PLQY.

To further elucidate the emission properties of $\mathrm{Cs}_{4} \mathrm{PbBr}_{6}$, we performed time-differentiated photoluminescence measurements. Interestingly, we found that the PL lifetimes in pure OD perovskite (Figure 4d) are 2.0 and $11.5 \mathrm{~ns}$ for short and long components, respectively, which are 2 orders of magnitude faster than those of $3 \mathrm{D}$ perovskite analogues. ${ }^{5,45}$ These fast radiative recombination rates may be attributed to the dramatic increase in the exciton binding energy (Table 1). As expected, the PL lifetime of the unwashed material increases (Figure 4d) due to the presence of three-dimensional $\mathrm{CsPbBr}_{3}$ with slow radiative recombination processes.

To check the stability of $0 \mathrm{D} \mathrm{Cs}_{4} \mathrm{PbBr}_{6}$, we measured its PLQY after storage for 3 weeks in ambient conditions (relative humidity of $57 \%$ ). Remarkably, the PLQY was $48 \%$ after such an extended storage, showing the promise of $\mathrm{Cs}_{4} \mathrm{PbBr}_{6}$ longterm stability.

In summary, we introduced a simple method for the separation of the monophasic $\mathrm{Cs}_{4} \mathrm{PbBr}_{6}$ solid and studied its emission properties. $\mathrm{Cs}_{4} \mathrm{PbBr}_{6}$ showed outstandingly high PLQY compared to its $3 \mathrm{D}$ perovskite counterpart and other perovskite derivatives reported in the literature. The coexistence of both $0 \mathrm{D}$ and $3 \mathrm{D}$ phases in previous reports on $\mathrm{Cs}_{4} \mathrm{PbBr}_{6}$ solids, as we showed here, has a severe detrimental effect on the emissive properties of $\mathrm{OD}$ perovskites. The methods and findings in this work pave the way for the applications of $\mathrm{Cs}-\mathrm{Pb}-\mathrm{Br}$ family perovskites. The emissive properties of $0 \mathrm{D}$ perovskite solids make them good candidate materials for color converters and light-emitting applications.

\section{ASSOCIATED CONTENT}

\section{S Supporting Information}

The Supporting Information is available free of charge on the ACS Publications website at DOI: 10.1021/acsenergylett.6b00396.
Details of all experimental procedures. optimization of the purification process, results of temperature-dependent PL measurements, and high-resolution powder XRD (PDF)

\section{AUTHOR INFORMATION}

\section{Corresponding Authors}

*E-mail: omar.abdelsaboor@kaust.edu.sa (O.F.M.).

*E-mail: osman.bakr@kaust.edu.sa (O.M.B.).

\section{Author Contributions}

${ }^{\dagger}$ M.I.S. and J.A. contributed equally to this work.

\section{Funding}

The authors acknowledge the support of King Abdullah University of Science and Technology (KAUST).

\section{Notes}

The authors declare no competing financial interest.

\section{REFERENCES}

(1) Miller, O. D.; Yablonovitch, E.; Kurtz, S. R. Strong Internal and External Luminescence as Solar Cells Approach the Shockley-Queisser Limit. IEEE J. Photovoltaics 2012, 2, 303-311.

(2) Lin, C. C.; Liu, R. S. Advances in Phosphors for Light-Emitting Diodes. J. Phys. Chem. Lett. 2011, 2, 1268-1277.

(3) Dursun, I.; Shen, C.; Parida, M. R.; Pan, J.; Sarmah, S. P.; Priante, D.; Alyami, N.; Liu, J.; Saidaminov, M. I.; Alias, M. S.; Abdelhady, A. L.; Ng, T. K.; Mohammed, O. F.; Ooi, B. S.; Bakr, O. M. Perovskite Nanocrystals as a Color Converter for Visible Light Communication. ACS Photonics 2016, 3, 1150-1156.

(4) Amani, M.; Lien, D.-H.; Kiriya, D.; Xiao, J.; Azcatl, A.; Noh, J.; Madhvapathy, S. R.; Addou, R.; KC, S.; Dubey, M.; Cho, K.; Wallace, R. M.; Lee, S.-C.; He, J.-H.; Ager, J. W.; Zhang, X.; Yablonovitch, E.; Javey, A. Near-Unity Photoluminescence Quantum Yield in $\mathrm{MoS}_{2}$. Science 2015, 350, 1065-1068.

(5) Shi, D.; Adinolfi, V.; Comin, R.; Yuan, M.; Alarousu, E.; Buin, A.; Chen, Y.; Hoogland, S.; Rothenberger, A.; Katsiev, K.; Losovyj, Y.; Zhang, X.; Dowben, P. A.; Mohammed, O. F.; Sargent, E. H.; Bakr, O. M. Low Trap-State Density and Long Carrier Diffusion in Organolead Trihalide Perovskite Single Crystals. Science 2015, 347, 519-522.

(6) Dong, Q.; Fang, Y.; Shao, Y.; Mulligan, P.; Qiu, J.; Cao, L.; Huang, J. Electron-Hole Diffusion Lengths $>175 \mu \mathrm{m}$ in SolutionGrown $\mathrm{CH}_{3} \mathrm{NH}_{3} \mathrm{PbI}_{3}$ Single Crystals. Science 2015, 347, 967-970.

(7) Manser, J. S.; Kamat, P. V. Band Filling with Free Charge Carriers in Organometal Halide Perovskites. Nat. Photonics 2014, 8, 737-743.

(8) Miyata, A.; Mitioglu, A.; Plochocka, P.; Portugall, O.; Wang, J. T.W.; Stranks, S. D.; Snaith, H. J.; Nicholas, R. J. Direct Measurement of the Exciton Binding Energy and Effective Masses for Charge Carriers in Organic-Inorganic Tri-Halide Perovskites. Nat. Phys. 2015, 11, $582-587$.

(9) D’Innocenzo, V.; Grancini, G.; Alcocer, M. J. P.; Kandada, A. R. S.; Stranks, S. D.; Lee, M. M.; Lanzani, G.; Snaith, H. J.; Petrozza, A. Excitons versus Free Charges in Organo-Lead Tri-Halide Perovskites. Nat. Commun. 2014, 5, 3586.

(10) Protesescu, L.; Yakunin, S.; Bodnarchuk, M. I.; Krieg, F.; Caputo, R.; Hendon, C. H.; Yang, R. X.; Walsh, A.; Kovalenko, M. V. Nanocrystals of Cesium Lead Halide Perovskites $\left(\mathrm{CsPbX}_{3}, \mathrm{X}=\mathrm{Cl}, \mathrm{Br}\right.$, 
and I): Novel Optoelectronic Materials Showing Bright Emission with Wide Color Gamut. Nano Lett. 2015, 15, 3692-3696.

(11) Dirin, D. N.; Protesescu, L.; Trummer, D.; Kochetygov, I. V.; Yakunin, S.; Krumeich, F.; Stadie, N. P.; Kovalenko, M. V. Harnessing Defect-Tolerance at the Nanoscale: Highly Luminescent Lead Halide Perovskite Nanocrystals in Mesoporous Silica Matrixes. Nano Lett. 2016, 16, 5866-5874.

(12) Cho, H.; Jeong, S.-H.; Park, M.-H.; Kim, Y.-H.; Wolf, C.; Lee, C.-L.; Heo, J. H.; Sadhanala, A.; Myoung, N.; Yoo, S.; Im, S. H.; Friend, R. H.; Lee, T.-W. Overcoming the Electroluminescence Efficiency Limitations of Perovskite Light-Emitting Diodes. Science 2015, 350, 1222-1225.

(13) Deschler, F.; Price, M.; Pathak, S.; Klintberg, L. E.; Jarausch, D. D.; Higler, R.; Hüttner, S.; Leijtens, T.; Stranks, S. D.; Snaith, H. J.; Atatüre, M.; Phillips, R. T.; Friend, R. H. High Photoluminescence Efficiency and Optically Pumped Lasing in Solution-Processed Mixed Halide Perovskite Semiconductors. J. Phys. Chem. Lett. 2014, 5, 14211426.

(14) Kim, Y.; Yassitepe, E.; Voznyy, O.; Comin, R.; Walters, G.; Gong, X.; Kanjanaboos, P.; Nogueira, A. F.; Sargent, E. H. Efficient Luminescence from Perovskite Quantum Dot Solids. ACS Appl. Mater. Interfaces 2015, 7, 25007-25013.

(15) Berhe, T. A.; Su, W.-N.; Chen, C.-H.; Pan, C.-J.; Cheng, J.-H.; Chen, H.-M.; Tsai, M.-C.; Chen, L.-Y.; Dubale, A. A.; Hwang, B.-J. Organometal Halide Perovskite Solar Cells: Degradation and Stability. Energy Environ. Sci. 2016, 9, 323-356.

(16) Kamminga, M. E.; Fang, H.-H.; Filip, M. R.; Giustino, F.; Baas, J.; Blake, G. R.; Loi, M. A.; Palstra, T. T. M. Confinement Effects in Low-Dimensional Lead Iodide Perovskite Hybrids. Chem. Mater. 2016, $28,4554-4562$.

(17) González-Carrero, S.; Galian, R. E.; Pérez-Prieto, J. Organometal Halide Perovskites: Bulk Low-Dimension Materials and Nanoparticles. Part. Part. Syst. Charact. 2015, 32, 709-720.

(18) Stoumpos, C. C.; Cao, D. H.; Clark, D. J.; Young, J.; Rondinelli, J. M.; Jang, J. I.; Hupp, J. T.; Kanatzidis, M. G. Ruddlesden-Popper Hybrid Lead Iodide Perovskite 2D Homologous Semiconductors. Chem. Mater. 2016, 28, 2852-2867.

(19) Saparov, B.; Mitzi, D. B. Organic-Inorganic Perovskites: Structural Versatility for Functional Materials Design. Chem. Rev. 2016, 116, 4558-4596.

(20) Tsai, H.; Nie, W.; Blancon, J.-C.; Stoumpos, C. C.; Asadpour, R.; Harutyunyan, B.; Neukirch, A. J.; Verduzco, R.; Crochet, J. J.; Tretiak, S.; Pedesseau, L.; Even, J.; Alam, M. A.; Gupta, G.; Lou, J.; Ajayan, P. M.; Bedzyk, M. J.; Kanatzidis, M. G.; Mohite, A. D. HighEfficiency Two-Dimensional Ruddlesden-Popper Perovskite Solar Cells. Nature 2016, 536, 312-316.

(21) Yuan, M.; Quan, L. N.; Comin, R.; Walters, G.; Sabatini, R.; Voznyy, O.; Hoogland, S.; Zhao, Y.; Beauregard, E. M.; Kanjanaboos, P.; Lu, Z.; Kim, D. H.; Sargent, E. H. Perovskite Energy Funnels for Efficient Light-Emitting Diodes. Nat. Nanotechnol. 2016, DOI: $10.1038 /$ nnano.2016.110.

(22) Dohner, E. R.; Jaffe, A.; Bradshaw, L. R.; Karunadasa, H. I. Intrinsic White-Light Emission from Layered Hybrid Perovskites. J. Am. Chem. Soc. 2014, 136, 13154-13157.

(23) Wang, K.-H.; Wu, L.; Li, L.; Yao, H.-B.; Qian, H.-S.; Yu, S.-H. Large-Scale Synthesis of Highly Luminescent Perovskite-Related $\mathrm{CsPb}_{2} \mathrm{Br}_{5}$ Nanoplatelets and Their Fast Anion Exchange. Angew. Chem., Int. Ed. 2016, 55, 8328-8332.

(24) Giorgi, G.; Yamashita, K. Zero-Dimensional Hybrid OrganicInorganic Halide Perovskite Modeling: Insights from First Principles. J. Phys. Chem. Lett. 2016, 7, 888-899.

(25) Saparov, B.; Sun, J.-P.; Meng, W.; Xiao, Z.; Duan, H.-S.; Gunawan, O.; Shin, D.; Hill, I. G.; Yan, Y.; Mitzi, D. B. Thin-Film Deposition and Characterization of a Sn-Deficient Perovskite Derivative $\mathrm{Cs}_{2} \mathrm{SnI}_{6}$. Chem. Mater. 2016, 28, 2315-2322.

(26) Bergerhoff, G.; Schmitz-Dumont, O. Die Kristallstruktur Des Kaliumhexachlorocadmats(II). Z. Anorg. Allg. Chem. 1956, 284, 1019.
(27) Kondo, S.; Amaya, K.; Saito, T. Localized Optical Absorption in $\mathrm{Cs}_{4} \mathrm{PbBr}_{6}$. J. Phys. Condens. Matter 2002, 14, 2093-2099.

(28) Nikl, M.; et al. Photoluminescence of $\mathrm{Cs}_{4} \mathrm{PbBr}_{6}$ Crystals and Thin Films. Chem. Phys. Lett. 1999, 306, 280-284.

(29) Velázquez, M.; Ferrier, A.; Péchev, S.; Gravereau, P.; Chaminade, J.-P.; Portier, X.; Moncorgé, R. Growth and Characterization of Pure and $\mathrm{Pr}^{3+}$-Doped $\mathrm{Cs}_{4} \mathrm{PbBr}_{6}$ Crystals. J. Cryst. Growth 2008, 310, 5458-5463.

(30) Andrews, R. H.; Clark, S. J.; Donaldson, J. D.; Dewan, J. C.; Silver, J. Solid-State Properties of Materials of the Type $\mathrm{Cs}_{4} \mathrm{MX}_{6}$ (Where $\mathrm{M}=\mathrm{Sn}$ or $\mathrm{Pb}$ and $\mathrm{X}=\mathrm{Cl}$ or $\mathrm{Br}$ ). J. Chem. Soc. Dalton Trans. 1983, 7, 767.

(31) Rakita, Y.; Kedem, N.; Gupta, S.; Sadhanala, A.; Kalchenko, V.; Böhm, M. L.; Kulbak, M.; Friend, R. H.; Cahen, D.; Hodes, G. LowTemperature Solution-Grown $\mathrm{CsPBBr}_{3}$ Single Crystals and Their Characterization. Cryst. Growth Des. 2016, DOI: 10.1021/ acs.cgd.6b00764.

(32) Saidaminov, M. I.; Abdelhady, A. L.; Murali, B.; Alarousu, E.; Burlakov, V. M.; Peng, W.; Dursun, I.; Wang, L.; He, Y.; Maculan, G.; Goriely, A.; Wu, T.; Mohammed, O. F.; Bakr, O. M. High-Quality Bulk Hybrid Perovskite Single Crystals within Minutes by Inverse Temperature Crystallization. Nat. Commun. 2015, 6, 7586.

(33) Zhang, T.; Yang, M.; Benson, E. E.; Li, Z.; van de Lagemaat, J.; Luther, J. M.; Yan, Y.; Zhu, K.; Zhao, Y. A Facile Solvothermal Growth of Single Crystal Mixed Halide Perovskite $\mathrm{CH}_{3} \mathrm{NH}_{3} \mathrm{~Pb}\left(\mathrm{Br}_{1-\mathrm{x}} \mathrm{Cl}_{\mathrm{x}}\right)_{3}$. Chem. Commun. 2015, 51, 7820-7823.

(34) Kadro, J. M.; Nonomura, K.; Gachet, D.; Grätzel, M.; Hagfeldt, A. Facile Route to Freestanding $\mathrm{CH}_{3} \mathrm{NH}_{3} \mathrm{PbI}_{3}$ Crystals Using Inverse Solubility. Sci. Rep. 2015, 5, 11654.

(35) Liu, Y.; Yang, Z.; Cui, D.; Ren, X.; Sun, J.; Liu, X.; Zhang, J.; Wei, Q.; Fan, H.; Yu, F.; Zhang, X.; Zhao, C.; Liu, S. F. Two-InchSized Perovskite $\mathrm{CH}_{3} \mathrm{NH}_{3} \mathrm{PbX}{ }_{3}(\mathrm{X}=\mathrm{Cl}, \mathrm{Br}, \mathrm{I})$ Crystals: Growth and Characterization. Adv. Mater. 2015, 27, 5176-5183.

(36) Saidaminov, M. I.; Haque, M. A.; Savoie, M.; Abdelhady, A. L.; Cho, N.; Dursun, I.; Buttner, U.; Alarousu, E.; Wu, T.; Bakr, O. M. Perovskite Photodetectors Operating in Both Narrowband and Broadband Regimes. Adv. Mater. 2016, DOI: 10.1002/ adma.201601235.

(37) Saidaminov, M. I.; Abdelhady, A. L.; Maculan, G.; Bakr, O. M. Retrograde Solubility of Formamidinium and Methylammonium Lead Halide Perovskites Enabling Rapid Single Crystal Growth. Chem. Commun. 2015, 51, 17658-17661.

(38) de Mello, J. C.; Wittmann, H. F.; Friend, R. H. An Improved Experimental Determination of External Photoluminescence Quantum Efficiency. Adv. Mater. 1997, 9, 230-232.

(39) Zhang, D.; Eaton, S. W.; Yu, Y.; Dou, L.; Yang, P. SolutionPhase Synthesis of Cesium Lead Halide Perovskite Nanowires. J. Am. Chem. Soc. 2015, 137, 9230-9233.

(40) Wu, K.; Bera, A.; Ma, C.; Du, Y.; Yang, Y.; Li, L.; Wu, T. Temperature-Dependent Excitonic Photoluminescence of Hybrid Organometal Halide Perovskite Films. Phys. Chem. Chem. Phys. 2014, 16, 22476-22481.

(41) Chen, Z.; Yu, C.; Shum, K.; Wang, J. J.; Pfenninger, W.; Vockic, N.; Midgley, J.; Kenney, J. T. Photoluminescence Study of Polycrystalline $\mathrm{CsSnI}_{3}$ Thin Films: Determination of Exciton Binding Energy. J. Lumin. 2012, 132, 345-349.

(42) Savenije, T. J.; Ponseca, C. S.; Kunneman, L.; Abdellah, M.; Zheng, K.; Tian, Y.; Zhu, Q.; Canton, S. E.; Scheblykin, I. G.; Pullerits, T.; Yartsev, A.; Sundström, V. Thermally Activated Exciton Dissociation and Recombination Control the Carrier Dynamics in Organometal Halide Perovskite. J. Phys. Chem. Lett. 2014, 5, 21892194.

(43) Ravi, V. K.; Markad, G. B.; Nag, A. Band Edge Energies and Excitonic Transition Probabilities of Colloidal $\mathrm{CsPbX}_{3}(\mathrm{X}=\mathrm{Cl}, \mathrm{Br}, \mathrm{I})$ Perovskite Nanocrystals. ACS Energy Lett. 2016, 3, 665-671.

(44) Zheng, K.; Zhu, Q.; Abdellah, M.; Messing, M. E.; Zhang, W.; Generalov, A.; Niu, Y.; Ribaud, L.; Canton, S. E.; Pullerits, T. Exciton Binding Energy and the Nature of Emissive States in Organometal Halide Perovskites. J. Phys. Chem. Lett. 2015, 6, 2969-2975. 
(45) Zhumekenov, A. A.; Saidaminov, M. I.; Haque, M. A.; Alarousu, E.; Sarmah, S. P.; Murali, B.; Dursun, I.; Miao, X.-H.; Abdelhady, A. L.; Wu, T.; Mohammed, O. F.; Bakr, O. M. Formamidinium Lead Halide Perovskite Crystals with Unprecedented Long Carrier Dynamics and Diffusion Length. ACS Energy Lett. 2016, 1, 32-37.

(46) Zhang, F.; Zhong, H.; Chen, C.; Wu, X.; Hu, X.; Huang, H.; Han, J.; Zou, B.; Dong, Y. Brightly Luminescent and Color-Tunable Colloidal $\mathrm{CH}_{3} \mathrm{NH}_{3} \mathrm{PbX}_{3}(\mathrm{X}=\mathrm{Br}, \mathrm{I}, \mathrm{Cl})$ Quantum Dots: Potential Alternatives for Display Technology. ACS Nano 2015, 9, 4533-4542.

(47) Ishihara, T.; Takahashi, J.; Goto, T. Exciton State in TwoDimensional Perovskite Semiconductor $\left(\mathrm{C}_{10} \mathrm{H}_{21} \mathrm{NH}_{3}\right)_{2} \mathrm{PbI}_{4}$. Solid State Commun. 1989, 69, 933-936.

(48) Yettapu, G. R.; Talukdar, D.; Sarkar, S.; Swarnkar, A.; Nag, A.; Ghosh, P.; Mandal, P. Terahertz Conductivity within Colloidal $\mathrm{CsPbBr}{ }_{3}$ Perovskite Nanocrystals: Remarkably High Carrier Mobilities and Large Diffusion Lengths. Nano Lett. 2016, 16, 4838-4848.

(49) Li, J.; Yuan, X.; Jing, P.; Li, J.; Wei, M.; Hua, J.; Zhao, J.; Tian, L. Temperature-Dependent Photoluminescence of Inorganic Perovskite Nanocrystal Films. RSC Adv. 2016, 6, 78311-78316. 